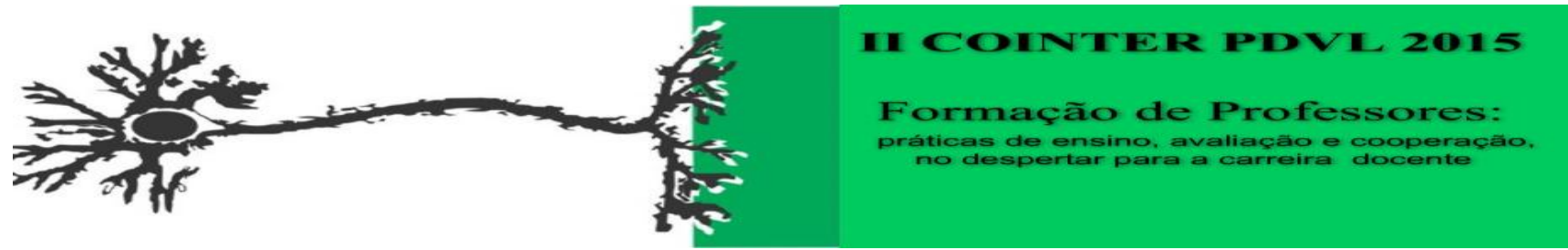

\title{
CÁLCULO DO RAIO DA TERRA UTILIZANDO UM TEODOLITO ELETRÔNICO: UMA ATIVIDADE EXTRACLASSE
}

\author{
Instituto Federal do Piauí, IFPI - Campus Teresina Central \\ Departamento de Formação de Professores \\ Roberto Arruda Lima Soares \\ E-mail: robertoarruda@ifpi.edu.br
}

\section{RESUMO}

A atividade extraclasse é de suma importância para formação dos discentes em todos os níveis do ensino básico e do ensino superior, pois proporciona que os conteúdos abordados em sala se consolidem com atividades praticadas num ambiente diferente. Também desperta o interesse pelo conhecimento mais aprofundado de determinado tema e estimula a pesquisa. Desta forma, o presente trabalho pretende apresentar os procedimentos e resultados de uma atividade extraclasse (cálculo do raio da Terra) com os alunos do curso de Licenciatura em Matemática do Instituto Federal do Piauí - Campus Teresina Central, assim como tal atividade pode influenciar a formação acadêmica e profissional destes discentes e futuros professores de matemática

PALAVRAS-CHAVE: atividade extraclasse, raio da Terra, formação acadêmica, professor de matemática. 


\section{INTRODUÇÃO}

O planeta Terra não é exatamente uma esfera perfeita, assim consideram-se três valores distintos, mas próximos, para o valor do seu raio natural. O raio polar de $6.357 \mathrm{~km}$, o raio equatorial $6.378 \mathrm{~km}$ e o raio considerando uma esfera perfeita $6.371 \mathrm{~km}$. Relatos históricos mostram que o raio da Terra foi calculado primeiramente por volta de $246 \mathrm{aC}$ pelo matemático e geógrafo grego Eratóstenes (276 - 196 a.C.) de Alexandria. Conhecendo a distância entre as cidades de Alexandria e Syene $(800 \mathrm{~km})$, a inclinação da incidência dos raios solares nas duas cidades num determinado dia do ano (solstício de verão no hemisfério norte) e aplicando o Teorema das Paralelas e regra de três simples, foi possível chegar ao resultado do comprimento do raio da Terra de $6.365 \mathrm{~km}$.

\section{Figura 1 - Representação geométrica a algébrica do cálculo do raio da Terra por Eratóstenes.}

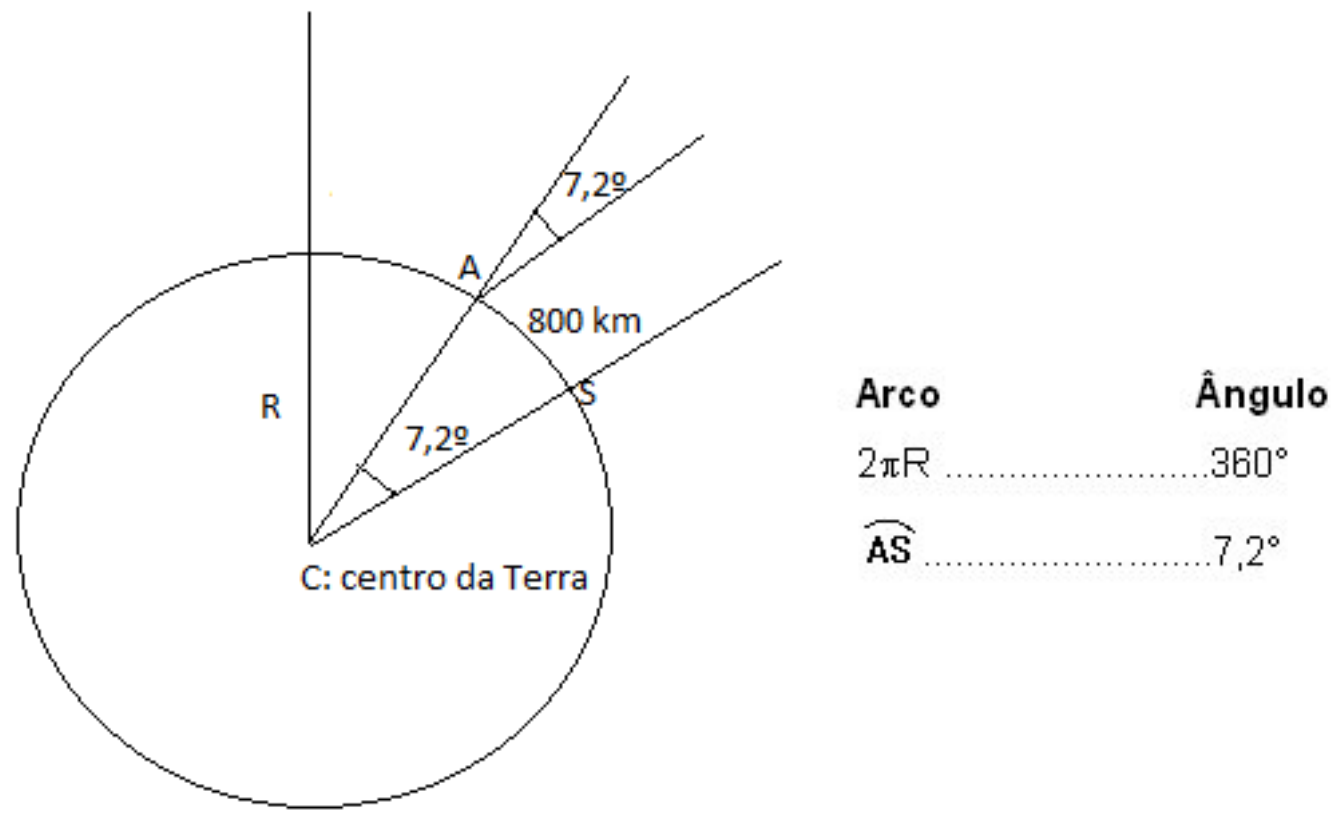

É possível realizar o cálculo do raio da Terra coletando os dados a beira mar onde é possível ver a linha do horizonte. A aula extraclasse experimental vem recebendo cada vez mais adeptos, pela sua eficiência no processo ensino-aprendizagem, pois dinamiza o aprendizado e consolida os conteúdos abordados em sala de aula através da convivência, prática e experimentação. Assim, o presente trabalho tem como objetivo apresentar o resultado de uma aula extraclasse - cálculo do raio da Terra considerando-a como uma esfera perfeita - e avaliar a influência que esta atividade pode promover na formação acadêmica e 
profissional dos alunos do curso de Licenciatura de Matemática do IFPI - Campus Teresina Central.

\section{MATERIAIS E MÉTODO}

Antes da execução da atividade extraclasse foi repassada em sala de aula a fundamentação teórica e demais informações pertinentes a atividade prática. Para realização da aula extraclasse foram utilizados um teodolito, trena, calculadora científica, caneta e bloco de anotações. O experimento foi realizado próximo ao mar na cidade de Luis Correia - PI na praia de Atalaia e teve os seguintes procedimentos:

1) Instalação e nivelamento do teodolito numa guarita para salva-vidas na praia de Atalaia;

2) Medição com a trena da altura do teodolito mais a altura da guarita totalizando $3,94 \mathrm{~m}$ e da distância da guarita até a beira mar $(219,60 \mathrm{~m})$, onde estava fixada uma estaca previamente colocada;

3) Medição com o teodolito do ângulo formado pelo centro da base do teodolito e a estaca fixada a beira mar. Também foi realizada a medição do ângulo formado pela base do teodolito e a linha do horizonte (lugar onde o céu e a água do mar parecem que se unem). Os valores obtidos nestas duas medidas foram, respectivamente, 88 $15^{\prime} 18^{\prime}$ ' e 89 $55^{\prime} 03^{\prime \prime}$;

4) Cálculo da altura do teodolito em relação ao nível do mar e com este resultado, o cálculo do raio da Terra e avaliação dos resultados obtidos;

5) Entrevista com os discentes que participaram da aula experimental. 
Figura 2 - Local da realização da aula experimental em Luis Correia - PI
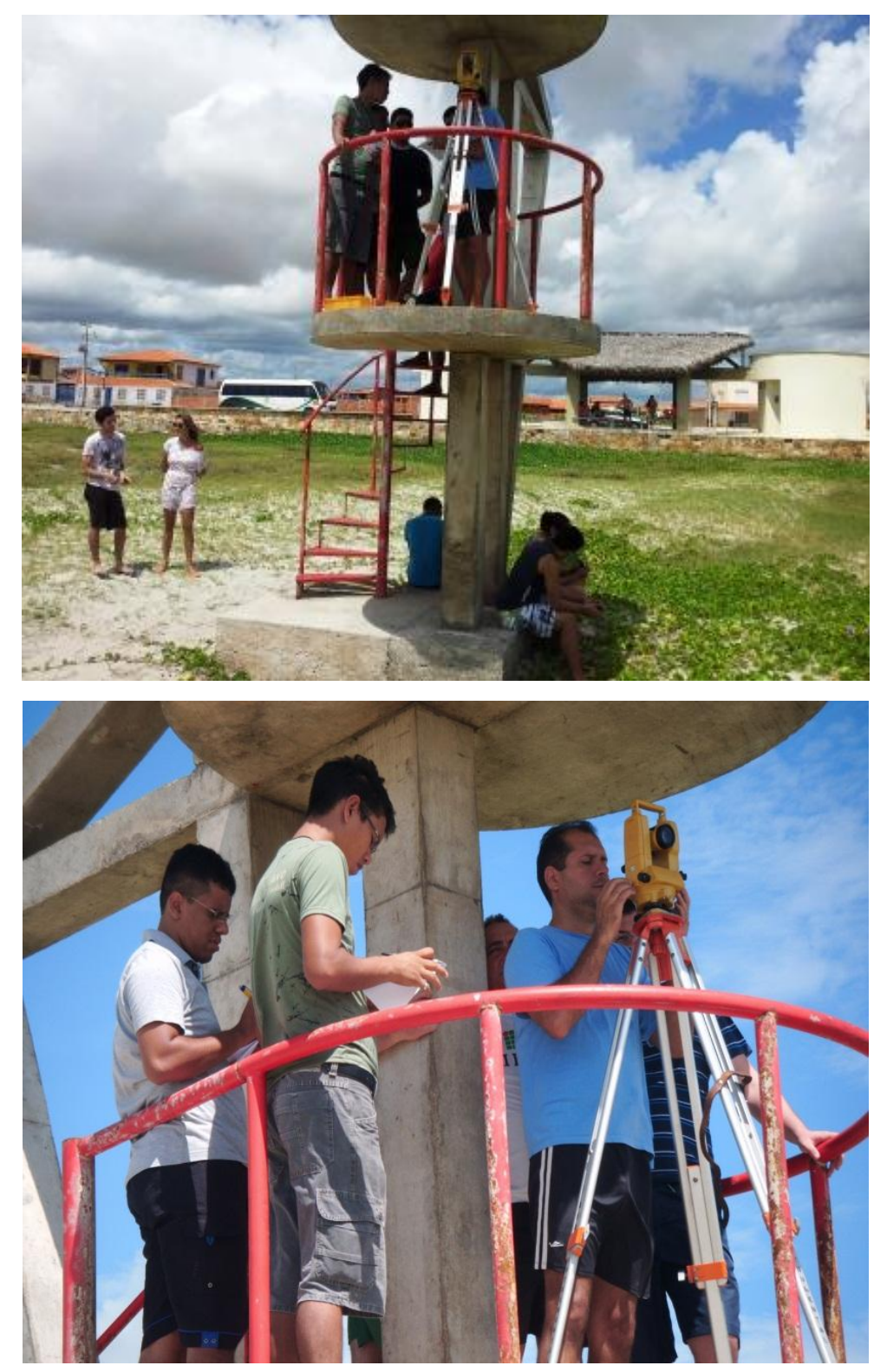

As medições da distância da guarita até a beira mar e do ângulo formado com o centro da base do teodolito e a estaca foram utilizadas para o cálculo da altura do teodolito em relação ao nível do mar $(\mathrm{h}=\mathrm{x}+3,94 \mathrm{~m})$ de acordo com a esquematização apresentada na Figura 3: 
Figura 3 - Esquematização matemática para o cálculo da altura do teodolito até o nível do mar.

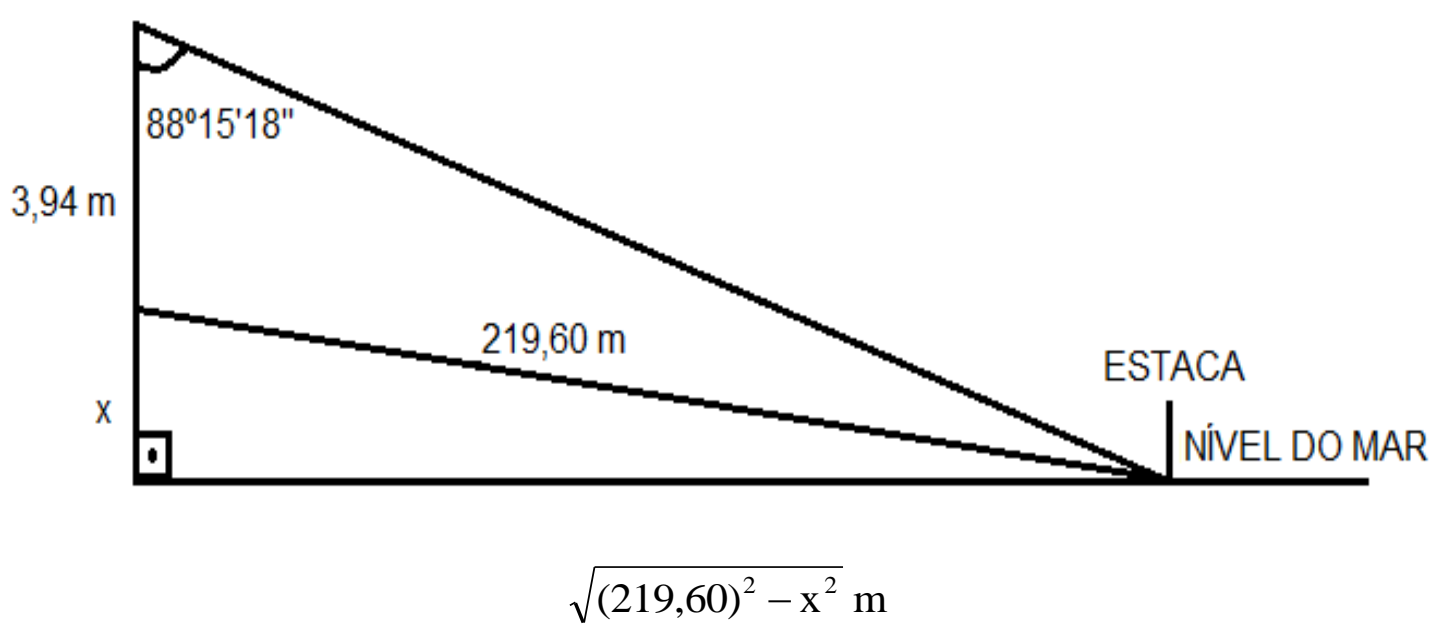

Para encontrar o valor de x (altura da base da guarita até o nível do mar) foi utilizada uma relação trigonométrica no triângulo retângulo de acordo com a Equação 1:

$$
\operatorname{tg}\left(88^{\circ} 15^{\prime} 18^{\prime \prime}\right)=\frac{\sqrt{(219,60)^{2}-x^{2}}}{3,94+x}
$$

Para o cálculo do raio da Terra foram utilizadas as medidas da distância do teodolito até o nível do mar (h) e o ângulo formado do centro da base do teodolito com o horizonte segundo o esquema apresentado na Figura 4: 
Figura 4: Esquema matemático para o cálculo do raio da Terra.

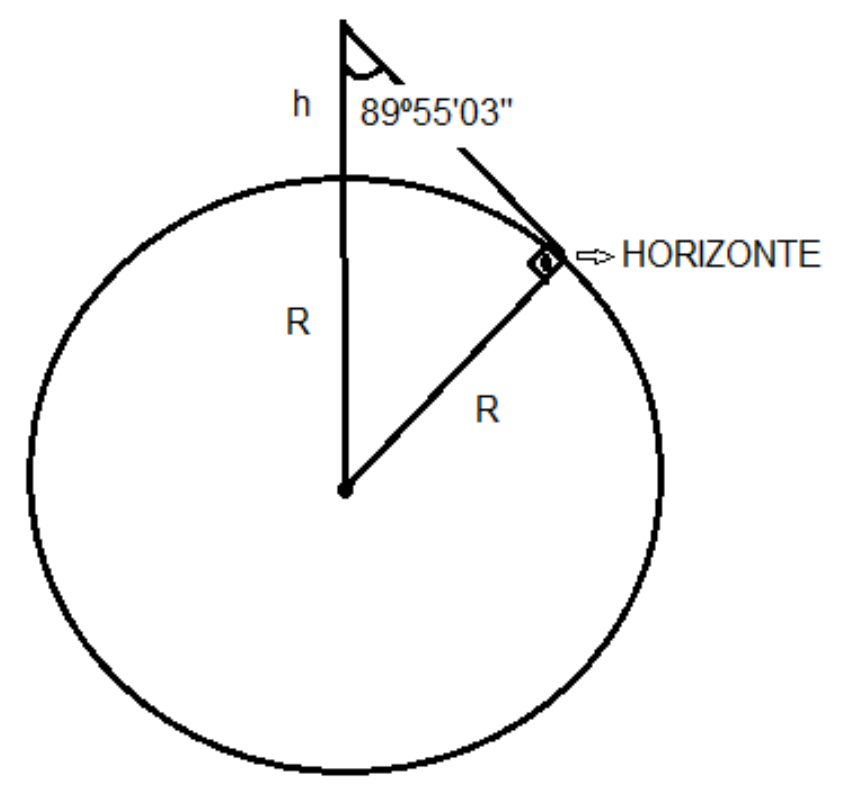

No cálculo do raio da Terra também foi utilizada uma relação trigonométrica no triângulo retângulo chegando ao valor do raio de acordo com a Equação 2:

$$
\mathrm{R}=\frac{h \cdot \operatorname{sen}\left(89^{\circ} 55^{\prime} 03^{\prime \prime}\right)}{1-\operatorname{sen}\left(89^{\circ} 55^{\prime} 03^{\prime \prime}\right)}
$$

Tem-se a seguir os resultados obtidos na aula experimental com sua respectiva discussão.

\section{RESULTADOS E DISCUSSÃO}

A solução da Equação 1 apresentou um valor para $\mathbf{x}$ de $2,75 \mathrm{~m}$, assim a altura $\mathrm{h}$ do teodolito até o nível do mar foi de 6,69 m. Com este resultado foi possível resolver a Equação 2 na qual se obteve o valor do raio da terra de $\mathrm{R}=6.453,012 \mathrm{~km}$. Assim o raio encontrado no experimento foi aproximadamente $82 \mathrm{~km}$ maior que o raio oficial $(6.371 \mathrm{~km})$ quando considerado a Terra como uma esfera perfeita, ou seja, com um erro equivalente a 1,3\%. É natural a ocorrência de erros quando se realiza um experimento nestas condições apresentadas. A sua ocorrência pode ser consequência das próprias condições naturais como: a mudança constante do nível do mar; distorções visuais provocadas pela incidência dos raios solares; discreto desnivelamento do teodolito promovido pela forte atividade eólica a beira mar. Assim como também pode ser consequência de erro humano cometido em alguma etapa de execução do experimento. 
Os relatos dos alunos que participaram da atividade extraclasse destacam que a aula prática contribuiu de forma significativa em sua formação acadêmica, pois se verificou com o experimento o que se conhecia apenas na teoria, assim ficou evidenciado que teoria e prática é essencial no processo ensino-aprendizagem. Ao mesmo tempo em que se verificou que o rigor na execução em cada etapa do procedimento experimental é muito importante para se obter o resultado esperado, e que isto nem sempre é possível sobre determinadas condições. Todos afirmaram que pretendem adotar, sempre que possível, atividades extraclasse com seus alunos durante sua vida profissional, ou seja, a aula experimental promoveu a formação de multiplicadores deste tipo de atividade que está de acordo com as tendências pedagógica atuais. Também despertou o interesse por parte dos discentes em desenvolver pesquisas de cunho experimental.

\section{CONCLUSÕES}

De acordo com o exposto, verificou-se que:

- O resultado valor da medida do raio foi maior $1,3 \%$ que o valor oficial. Isto se deve as possíveis interferências naturais ou erro humano cometido na execução experimento.

- A atividade extraclasse influenciou de forma significativa na formação dos discentes do curso de Matemática do IFPI - Campus Teresina Central que participaram da aula experimental, pois mostrou que as atividades extraclasse tem um grande potencial pedagógico em todos os níveis do ensino, promovendo a formação de novos pesquisadores e professores multiplicadores de tais práticas pedagógicas.

\section{AGRADECIMENTOS}

Agradeço ao Instituto Federal do Piauí pelo apoio financeiro e logístico para a realização do presente trabalho.

\section{REFERÊNCIAS}

1. BOYER, Carl B. História da Matemática. São Paulo: Edgard Blücher, 1991.

2. LIMA, Elon Lages, Meu Professor de Matemática e outras Histórias. Rio de Janeiro, SBM, 1991. 
3. MILIES, Francisco César Polcino, BUSSAB, José Hugo de Oliveira. A geometria na Antiguidade Clássica. São Paulo: FTD, 1999.

4. O. DOLCE, J. N. Pompeo. Fundamentos da Matemática Elementar: Geometria espacial, posição e métrica. Vol. 10, Ed. 5, editora Atual, 2010.

5. SPERANDIO, Décio; MENDES, João Teixeira; SILVA, Luiz Henry Monken e. Cálculo numérico: características matemáticas e computacionais dos métodos numéricos . São Paulo: Pearson Education do Brasil, c2003. 